\title{
Ulinastatin Reduces T Cell Apoptosis in Rats with Severe Acute Pancreatitis
}

\author{
Chunli Wang, Tao Ma, Xiaolei Zhou, Nan Li and Shengyi You* \\ Department of General Surgery, General Hospital of Tianjin Medical University, Tianjin 300052, China
}

*For correspondence: Email: shengyiyou@139.com

Received: 20 October 2013

Revised accepted: 12 December 2013

\begin{abstract}
Purpose: To investigate the immunoregulative effects of ulinastatin (UTI) on T lymphocytes apoptosis in rats with severe acute pancreatitis (SAP) and to elucidate its underlying molecular mechanism.

Methods: Thirty six Wistar rats were randomly divided into 3 groups $(n=12):$ sham, SAP model and UTI-treated group. SAP model was established by intrapancreatobiliary duct injection of 5\% sodium taurocholate. A bolus of $10000 \mathrm{U} / \mathrm{kg}$ UTI was intravenously injected after SAP establishment. T cell apoptosis was determined by Annexin-V/PI double-staining. Oxidative stress was evaluated by examining changes in the levels of reactive oxygen species (ROS). Total superoxide dismutase (SOD) in serum was tested by hydroxylamine colorimetric assay, and malondialdehyde levels were examined by thiobarbituric acid assay. Mitochondrial function was evaluated by analyzing mitochondrial membrane potential (MMP) and mitochondrial permeability transition pore (MPTP).

Results: We found $C D_{4}{ }^{+} T$ cells $(32.10 \pm 2.87 \%$ vs. $45.22 \pm 4.38 \%, P<0.01)$ and $C D_{4}{ }^{+} / C D_{8}{ }^{+} T$ cells in $S A P$ rats significantly decreased compared with sham group $(1.15 \pm 0.12$ vs. $2.23 \pm 0.12 \%, P<0.01)$, while the percent of the apoptotic $C D_{4}^{+}$and $(17.70 \pm 2.10$ vs. $3.82 \pm 0.50 \%, P<0.01) C D_{8}^{+}{ }^{+} T$ lymphocytes was highly increased $(2.78 \pm 0.45$ vs. $1.97 \pm 0.36 \%, P<0.01$ compared with sham group). After UTI treatment, the

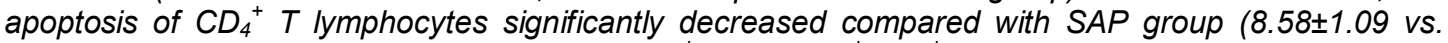
$17.70 \pm 2.10 \%, P<0.01$ ), while the percent of $C D_{4}^{+} T$ and $C D_{4}^{+} / C D_{8}{ }^{+}$lymphocytes significantly enhanced $(P<0.01)$. ROS (mean fluorescence intensity): $5107 \pm 430$ vs. $12904 \pm 840, P<0.01)$ and MDA levels $(4.41 \pm 0.32$ vs. $7.25 \pm 0.57 \mathrm{nmol} / \mathrm{ml}, \quad P<0.01)$ in serum in UTI-treated group were decreased compared with SAP group. SOD activity was enhanced after UTI treatment $(59.72 \pm 5.45 \mathrm{vs} .48 .32 \pm 3.81 \mathrm{nmol} / \mathrm{ml}$, $P<0.01)$. Mitochondrial function assays showed that MMP $(17.30 \pm 1.60$ vs. $46.94 \pm 3.49 \%, P<0.01)$ and MPT (30.14 2.46 vs. $51.31 \pm 3.23 \%, P<0.01)$ were inhibited by UTI.

Conclusion: UTI reduces T lymphocytes apoptosis and improves immunological function in SAP rats, possibly via enhancing the scavenging capacity of oxygen free radical and attenuating the influence of oxidative stress.
\end{abstract}

Key words: Ulinastatin, T cell, Apoptosis, Severe acute pancreatitis, Mitochondrion.

Tropical Journal of Pharmaceutical Research is indexed by Science Citation Index (SciSearch), Scopus, International Pharmaceutical Abstract, Chemical Abstracts, Embase, Index Copernicus, EBSCO, African Index Medicus, JournalSeek, Journal Citation Reports/Science Edition, Directory of Open Access Journals (DOAJ), African Journal Online, Bioline International, Open-J-Gate and Pharmacy Abstracts

\section{INTRODUCTION}

Severe acute pancreatitis (SAP) is a systematic disease with ongoing immune disorder. In the early stage, it is characterized by overdue inflammatory reaction, with its major clinical manifestation of systematic immune syndrome
(SIRS) and the functional damage of related organs like cardiovascular, lungs and kidney [1]. In the late stage, the severe suppression of immune function is the fundamental cause of infection [2], which is manifested by disproportion of CD4/CD8, T helper cell (Th1/Th2) shift, the anergy of lymphocytes and most prominently, the excessive apoptosis of lymphocytes. The 
excessive apoptosis of lymphocytes is the critical link that causes the dysfunction of immune system. Large amount of scavenging by the apoptosis of lymphocytes attenuates the number of lymphocytes with biological activity.

It has been demonstrated that oxidative stress (OS) is closely related to lymphocyte apoptosis [3]. As the fundamental organelles to determine the destiny of cells [4], mitochondria are the target of the ROS injury and an important origin of ROS as well [5].

Ulinastatin (UTI) is the glycoprotein separated and purified from the urine of healthy adult men. As an endogenous protective mechanism, UTI can antagonize stress and attenuate organ injury. Researchers have demonstrated that UTI has a strong enzyme inhibitory activity [6], enabling it to inactivate multiple enzymes. Furthermore, UTI has anti-inflammatory activity and can directly inhibit inflammatory mediators and inflammatory cytokines such as TNF- $\alpha$, IL-1 and IL-8 [7]. Therefore, UTI is widely applied to pancreatitis therapy due to its ability to reduce many critical factors including the pancreative activity and the release of inflammatory mediators [8].

It has also been suggested that UTI improves immune function [9]. Given the therapeutical value of UTI and ROS production [10], we assumed that UTI may exert immunoinhibitory effects on SAP. In the present study, we investigated the immunoregulatory effects of UTI on $\mathrm{T}$ lymphocytes apoptosis in SAP rat model and elucidated the underlying molecular mechanism.

\section{MATERIALS AND METHODS}

\section{Animals}

Thirty six Wistar rats (250-300g, 3 months old, 18 males and 18 females), were purchased from Animal Laboratory Centre, Academy of Military Medical Sciences of PLA (license: SCXK 2009003). Animals were kept in clean separate cages with free access to food and water, where room temperature remained between $20^{\circ} \mathrm{C}$ to $29^{\circ} \mathrm{C}$ in the dry aeration atmosphere, for 12 hours under fluorescent illumination to maintain the diurnal cycle. All the animal experiments were performed in accordance with the guidelines for animal research from the National Animal Center of China (No.95-38, revised 1995). All experimental protocols were approved by the Animal Care and Use Committee of Tianjin Medical University and were conducted according to the Helsinki Declaration.

\section{Animal grouping and establishment of SAP model}

Rats were randomly divided into 3 groups $(n=12)$ after one week of adaptive feed: (1) shamoperated control group; (2) SAP group; (3) UTItreated group. Animals were fasted for 12 hours before operation, with free access to water. Each rat was intraperitoneally administered with $10 \%$ chloral hydrate according to the weight that is, $300 \mathrm{mg} / \mathrm{kg}$. Abdominal skin preparation and disinfection was given after anesthesia. Then central abdominal incision below the xiphoid process was made under aseptic operation. The lower margin of the liver, the duodenum, the pancreatic duct and the partial pancreas were exposed. Puncture was carried out using disposable IV catheter through the lateral wall on the duodenum where the two cholecystopancreatic ducts form an opening. Part of the needle core was withdrawn immediately after insertion into the duodenal cavity. Then the trocar enters approximately 0.5 $\mathrm{cm}$ along the opening of the cholecystopancreatic duct and the needle core was completely pulled out. Cholecystopancreatic duct in the hilar region was clamped with a microclip to prevent the sodium taurocholate from injecting into the liver and the end of the intubation was connected to the syringe pump.

In the SAP model group and UTI-treated group, animals were injected with $5 \%$ sodium taurocholate at the speed of $0.1 \mathrm{ml} / \mathrm{min}$ according to the weight that is, $1 \mathrm{ml} / \mathrm{kg}$. Five minuites after injection, the intubation and artery occlusion were removed and the pin hole was wiped on the duodenal wall with $100 \%$ alcohol to make it contract to prevent the outflow of the intestinal contents. In the sham group, injection of sodium taurocholate was excluded. Other operations are the same as the other two groups. After operation, animals in each group recieved the interval subcutaneous injection of $5 \%$ glucose and sodium oxide of $50 \mathrm{ml} / \mathrm{kg}$. Following the development of the SAP model, animals in the UTI-treated group received injection of UTI through the tail vein of $10000 \mathrm{U} / \mathrm{kg}$. All the animals were taken postoperative insulation and incision care to avoid asphyxia death caused by the rats' scratching and biting the suture or their vomit.

\section{Separation of spleen lymphocytes}

Suspensions of spleen $\mathrm{T}$ cells were cultured at a density of $2 \times 10^{5}$ well in RPMI 1640 medium supplemented with $5 \%$ heat-inactivated fetal bovine serum, $2 \mathrm{mM}$ L-glutamine, $100 \mathrm{U} / \mathrm{ml}$ 
penicillin and $100 \mu \mathrm{g} / \mathrm{ml}$ streptomycin in a humidified incubator, at $37^{\circ} \mathrm{C}$ with $5 \% \mathrm{CO}_{2}$.

MagCellect rat $\mathrm{CD}^{+} \mathrm{T}$ cell isolation kit (R\&DSystems, Minneapolis, MN, USA) was used according to the manufacturer's recommendation to isolate splenic $\mathrm{T}$ cells $(\mathrm{C} 3 \mathrm{H})$. Then, these were stained with FITC-conjugated anti-CD4 or PEconjugated anti-CD8 antibody (BD Biosciences PharMingen).

\section{Analysis of $\mathrm{T}$ cell apoptosis by flow cytometry}

$\mathrm{T}$ cells were harvested and resuspended in binding buffer. The cell suspension was incubated with FITC Annexin-V (BD Biosciences, USA) and propidium iodide (PI) for $15 \mathrm{~min}$ at room temperature in dark followed by flow cytometry analysis. The percentage of cells positive for Annexin-V, PI alone and in combination was calculated by dot plot analysis using Cell Quest Pro software (FCM-500, Beckman).

Determination of malondialdehyde (MDA) production and superoxide dismutase (SOD) activity

The levels of SOD and MDA, special markers for reactive oxygen species (ROS), were determined in the sera of mice. The MDA level and SOD activity were analyzed using specific reagents according to the protocols provided by the manufacturer (Nanjing Jiancheng Bioengineering Institute, China). Briefly, thiobarbituric acid was used as substrate for the detection of MDA, and the xanthine oxidase method was used for the detection of SOD activity.

\section{Mitochondrial membrane potential assay}

An reagent, 5,5',6,6'- tetrachloro-1,1',3,3' tetraethylbenzimidazoly-carbocyanine iodide (JC1), was used to assess mitochondrial potential changes using confocal microscope. Briefly, cells in 24-well plates at a density of $1 \times 10^{5}$ cells $/ \mathrm{ml}$ cultured at 37C overnight for $24 \mathrm{hrs}$ before addition of $1 \mu \mathrm{g} / \mathrm{ml} \mathrm{JC}-1$ in culture media for 30 min. The cells were examined by confocal microscope (Nikon, Japan). Changes in the fluorescence from red to green indicate the changes in mitochondrial membrane potential; the green/red ratio was calculated from the changes in the intensity of red and green fluorescence assessed using a computer program.

\section{Determination of mitochondrial permeability transition}

Mitochondrial permeability transition was determined by MitoProbe transition pore assay kit (Molecular Probes Inc., Eugene, OR, USA), a technique based on calcein acetoxymethyl ester (AM) and $\mathrm{CoCl} 2$.

\section{Statistical analysis}

The data was analyzed with SPSS18.0 software. The measurement data was expressed as $X \pm S$, the multiple mean comparison was evaluated by one way ANOVA, and the comparison between any two means by LSD test. The significant difference was $\mathrm{P}<0.05$.

\section{RESULTS}

\section{Ratio of $\mathrm{CD}_{4}{ }^{+}$to $\mathrm{CD}_{8}{ }^{+} \mathrm{T}$ cell subsets}

As shown in Table 1, we found the percents of $\mathrm{CD}_{4}{ }^{+} \mathrm{T}$ cells $(32.10 \pm 2.87 \%$ vs. $45.22 \pm 4.38 \%$, $p<0.01$ ) and $\mathrm{CD}_{4}{ }^{+} / \mathrm{CD}_{8}{ }^{+} \mathrm{T}$ cells in SAP rats significantly decreased compared with sham group $(1.15 \pm 0.12$ vs. $2.23 \pm 0.12 \%, p<0.01)$

Table 1: Ratio of $\mathrm{CD}_{4}{ }^{+}$to $\mathrm{CD}_{8}{ }^{+} \mathrm{T}$ cell subsets in each group $(n=12)$

\begin{tabular}{llll}
\hline Group & $\mathbf{C D}_{4}{ }^{+}(\%)$ & $\mathbf{C D}_{8}{ }^{+}(\%)$ & $\mathbf{C D}_{4}{ }^{+} / \mathbf{C D}_{8}{ }^{+}$ \\
\hline Sham & $45.22 \pm 4.38$ & $20.28 \pm 2.11$ & $2.23 \pm 0.12$ \\
SAP & $32.10 \pm 2.87^{*}$ & $28.41 \pm 2.31$ & $1.15 \pm 0.12^{*}$ \\
Ulinastatin & $37.63 \pm 3.41^{\#}$ & $24.31 \pm 2.62$ & $1.66 \pm 0.12^{\#}$ \\
\hline \multicolumn{2}{l}{ All the values are given as mean \pm SEM; ${ }^{*} p<0.01 \mathrm{vs}}$. \\
control group $;{ }^{\# P}<0.01$ vs. SAP group
\end{tabular}

\section{Ratio of $\mathrm{CD}_{4}{ }^{+}$to $\mathrm{CD}_{8}{ }^{+} \mathrm{T}$ cell subset apoptosis}

By using annexin V/PI Double Staining, we observed that the percent of apoptotic $\mathrm{CD}_{4}{ }^{+} \mathrm{T}$ cells and $(17.70 \pm 2.10$ vs. $3.82 \pm 0.50 \%, p<$ 0.01 ) apoptotic $\mathrm{CD}_{8}^{+} \mathrm{T}$ cells in the SAP group greatly increased $(2.78 \pm 0.45$ vs. $1.97 \pm 0.36 \%$, $p<0.01$ ) in comparison with sham group. After UTI treatment, the apoptosis of $\mathrm{CD}_{4}{ }^{+} \mathrm{T}$ lymphocytes in the SAP rats significantly decreased $(8.58 \pm 1.09$ vs. $17.70 \pm 2.10 \%, p<$ $0.01)$, but the percent $\mathrm{CD}_{4}{ }^{+} \mathrm{T}$ and $\mathrm{CD}_{4}{ }^{+} / \mathrm{CD}_{8}{ }^{+}$ lymphocytes markedly enhanced $(p<0.01)$. (Table 2).

\section{ROS Level in spleen lymphocytes}

As seen from Table 3, ROS (MFI: $5107 \pm 430$ vs. $12904 \pm 840, P<0.01)$ and MDA levels $(4.41 \pm 0.32$ vs. $7.25 \pm 0.57 \mathrm{nmol} / \mathrm{ml}, \mathrm{P}<0.01)$ in serum in UTItreated group were decreased. SOD activity was 
enhanced after UTI treatment $(59.72 \pm 5.45$ vs. $48.32 \pm 3.81 \mathrm{nmol} / \mathrm{ml}, \mathrm{P}<0.01$ ) (Table 4).

Table 2: Apoptosis of $\mathrm{CD}_{4}{ }^{+}, \mathrm{CD}_{8}{ }^{+} \mathrm{T}$ cells subsets in each group $(n=12)$

\begin{tabular}{lll}
\hline Group & $\begin{array}{l}\mathrm{CD}_{4}{ }^{+} \mathrm{T} \text { cells } \\
\text { subset } \\
\text { apoptosis (\%) }\end{array}$ & $\begin{array}{l}\mathrm{CD}_{8}{ }^{+} \mathrm{T} \text { cells } \\
\text { subset } \\
\text { apoptosis } \\
\mathbf{( \% )}\end{array}$ \\
\hline Control & $3.82 \pm 0.50$ & $1.97 \pm 0.36$ \\
SAP & $17.70 \pm 2.10^{*}$ & $2.78 \pm 0.45^{*}$ \\
Ulinastatin & $8.58 \pm 1.09 \#$ & $2.46 \pm 0.36 \mathbf{A}$
\end{tabular}

All the values are given as mean \pm SEM; ${ }^{*} p<0.01 \mathrm{vs}$. control group; ${ }^{\#} p<0.01$ vs. SAP group; ${ }^{\wedge} p>0.05$ vs. SAP group

Table 3: ROS level in spleen lymphocytes for each group $(n=12)$

\begin{tabular}{ll}
\hline Group & $\begin{array}{l}\text { Mean fluorescence } \\
\text { intensity of ROS }\end{array}$ \\
\hline Sham & $467 \pm 48$ \\
SAP & $12904 \pm 840^{*}$ \\
Ulinastatin & $5107 \pm 430 \#$ \\
\hline $\begin{array}{l}\text { All values are given as mean } \pm S E M ;{ }^{*} p<0.01 \text { vs. } \\
\text { control; }{ }^{\#} p<0.01 \text { vs. SAP group }\end{array}$
\end{tabular}

Table 4: Serum SOD activity and MDA level for each group $(n=12)$

\begin{tabular}{lll}
\hline Group & $\begin{array}{l}\text { SOD activity } \\
\text { (U/ml) }^{*}\end{array}$ & $\begin{array}{l}\text { MDA level } \\
\text { (nmol/ml) }\end{array}$ \\
\hline Sham & $80.68 \pm 0.50$ & $2.27 \pm 0.26$ \\
SAP & $48.32 \pm 3.81^{*}$ & $7.25 \pm 0.57^{*}$ \\
Ulinastatin & $59.72 \pm 5.45 \#$ & $4.41 \pm 0.32 \#$ \\
\hline
\end{tabular}

All the values are given as mean \pm SEM; ${ }^{*} p<0.01 \mathrm{vs}$. control group; ${ }^{*} p<0.01$ vs. SAP group

\section{Spleen lymphocyte MMP}

Mitochondrial function was evaluated by analyzing mitochondrial membrane potential. It showed that MMP (17.30 \pm 1.60 vs. $46.94 \pm 3.49$ $\%, p<0.01)(30.14 \pm 2.46$ vs. $51.31 \pm 3.23 \%, p<$ 0.01 ) was inhibited by UTI (Table 5).

Table 5: The spleen lymphocyte MMP for each group $(n=12)$

\begin{tabular}{lc}
\hline Group & $\begin{array}{c}\text { Lymphocytes with } \\
\text { decreased MMP }(\%)\end{array}$ \\
\hline Sham & $3.69 \pm 0.45$ \\
SAP & $46.94 \pm 3.49^{*}$ \\
Ulinastatin & $17.30 \pm 1.60 \#$ \\
\hline All the values are given as mean \pm SEM; * $p<0.01$ vs. \\
control group; ${ }^{*} p<0.01$ vs. SAP group
\end{tabular}

\section{Opening level of the spleen lymphocyte MPTP}

Mitochondrial function was also evaluated by analyzing by mitochondrial permeability transition pore. As shown in Table 6, compared with SAP group, MPT (30.14 \pm 2.46 vs. $51.31 \pm 3.23 \%, p$ $<0.01$ ) was inhibited in UTI-treated rats.

Table 6: Opening level of the spleen lymphocyte MPTP in each group $(n=12)$

\begin{tabular}{ll}
\hline Group & $\begin{array}{l}\text { Lymphocytes with } \\
\text { abnormal opening of } \\
\text { MPTP (\%) }\end{array}$ \\
\hline Sham & $7.69 \pm 0.77$ \\
SAP & $51.31 \pm 3.23^{*}$ \\
Ulinastatin & $30.14 \pm 2.46 \#$ \\
\hline All the values are given as mean \pm SEM; ${ }^{*} p<0.01$ \\
vs. control group; ${ }^{\#} p<0.01$ vs. SAP grou
\end{tabular}

\section{DISCUSSION}

\section{UTI attenuates the abnormal apoptosis of CD4+ T lymphocytes in SAP rats}

Lymphocyte apoptosis is closely related immunosuppression [11]. Recent study has proved that immunosuppression is mainly caused by acceleration of lymphocytes apoptosis. Inflammation of the pancreas and its surrounding areas, caused by weakened immunity, is the commonest and severest complication and constitutes the main cause of death in the later progress of SAP, with mortality rate reaching $80 \%$ [12].

In our study, the percentage of apoptotic $\mathrm{CD}_{4}{ }^{+} T$ lymphocytes in the SAP group went up more noticeably than that of apoptotic $\mathrm{CD}_{8}{ }^{+} \mathrm{T}$ lymphocytes, which led to the phenomenon that the percentage of $\mathrm{CD}_{4}{ }^{+} \mathrm{T}$ lymphocytes and the ratio of $\mathrm{CD}_{4}{ }^{+}$and $\mathrm{CD}_{8}{ }^{+} \mathrm{T}$ lymphocytes in SAP group were remarkably lower than that in sham operation control group. It can be concluded that when SAP occurs, the body stimulates the apoptosis of $\mathrm{CD}_{4}{ }^{+} \mathrm{T}$ lymphocytes to downregulate inflammatory reaction. This can lighten the injury that resulted from excessive inflammatory reaction but will result in low cellular immune function which causes immunosuppression.

UTI, a glycoprotein secreted by the liver [13], can act on several key steps of pancreatic disease, such as activation of pancreatic enzymes and cytokines and release of inflammatory mediators, so it is widely applied in pancreatitis treatment [8]. In 2009, Huang et al demonstrated UTI can noticeably improve the living conditions of sepsis patients [14].

In this study, the proportion of $\mathrm{CD}_{4}{ }^{+} \mathrm{T}$ lymphocytes and ratio of $\mathrm{CD}_{4}{ }^{+}$and $\mathrm{CD}_{8}{ }^{+} \mathrm{T}$ lymphocytes in UTI-treated group has obviously picked up compared with the SAP group, mainly 
due to the fact that the percentage of apoptotic $\mathrm{CD}_{4}{ }^{+} \mathrm{T}$ lymphocytes decreased significantly while the proportion of apoptotic $\mathrm{CD}_{8}^{+} \mathrm{T}$ lymphocytes was almost the same with that in the SAP group. Through reducing abnormal apoptosis of $\mathrm{CD}_{4}^{+} \mathrm{T}$ lymphocytes in SAP rats, UTI has a direct effect in improving the state of immunodepression so as to reduce the susceptibility of secondary infection, prevent occurrence of septicopyemia and MODS and lower the mortality rate of SAP.

\section{UTI attenuates oxidative stress level in rats with SAP}

During the process of pancreatic damage, ROS can not only peroxidize fatty acids, but also destroy the lipid membrane and lysosomal membrane, causing injury to the gland. Moreover, in the cases of peripancreatic injury, ROS is the key factor which generates cytokines and inflammatory mediator cascade, mediates inflammatory cell infiltration, endothelial dysfunction and microcirculation dysfunction, thereby resulting in organ lesions. ROS level is closely related to the degree of apoptosis the lymphocytes [3].

The following reasons may mainly account for the increase of oxygen free radical in SAP: Bile salts, trypsin and chymotrypsin activate xanthine oxidase, which catalyzes the oxidation of hypoxanthine to xanthine and produce a great number of oxygen free radicals [15]. Inflammatory mediators like thromboxane can engender neutrophil chemotaxis and produce oxygen free radicals through respiratory burst.

SOD can effectively scavenge superoxide anion radicals produced in the metabolic process, whose activity can indirectly reflect the body's ability to eliminate the oxygen free radicals. MDA is one of the major aldehyde formed via lipid peroxidation, whose contents can reflect the degree of the body's lipid peroxidation and indirectly reflect the severity of oxygen free radicals' attack on cells. Therefore the SOD activity and the MDA contents can reflect the equilibrium condition between the body's oxidation and anti-oxidation.

The present study showed that UTI can resist lipid peroxidation induced by free radicals and their metabolic products. Furthermore, as a high efficiency, broad spectrum enzyme inhibitor, UTI can block the accumulation of neutrophils mediated by protease in lungs, inhibit the activity and the phagocytosis of the lysosomal enzyme in neutrophils, hence reducing the release of inflammatory mediators and oxygen free radicals and restricting the vicious cycle and magnified effect due to the cascade reaction of enzyme, cytokine and oxygen free radical. This study shows that UTI can significantly enhance the scavenging capacity of oxygen free radical, reduce the apoptotic ratio of lymphocytes, and attenuate the influence of oxidative stress on immunologic function in SAP rats through lowering the intracellular ROS production in splenic lymphocytes and the MDA contents in serum, and increasing the activity of SOD in serum as well.

The mitochondrial mechanism of UTI underlying its role of reducing apoptosis of $T$ lymphocytes

Mitochondria are not only the place for tricarboxylic acid cycle, oxidative phosphorylation and fatty acid oxidation, but also a crucial organelle for apoptosis [16]. As a key organelle [4] which could decide a cell's fate--- survival or apoptosis, mitochondrion is both the damage target point and significant source of ROS [5]. Though it is the main place for the generation of ROS, excessive ROS could result in the damage of mitochondrial oxidative stress and respiratory chain dysfunction, which will in reverse stimulate mitochondria to produce more ROS. This vicious circle could gradually lead mitochondria to dysfunction and finally damage cell function and viability [17]. Data shows that mitochondrion is also a vital source for ROS in T lymphocyte. Large quantities of energy is needed for $T$ lymphocyte to activate and proliferate, which could cause over polarization of mitochondrial membrane and further fierce oxidative phosphorylation, and more electrons overflow from the respiratory chain to bring more ROS [18]. The accumulated ROS in mitochondrion could result in its DNA mutation, lipid peroxidation and open-up MPTP, which could finally affect its structure and function. According to some studies, the key factors which could open up MPTP are excessive $\mathrm{Ca}^{2+}$ in mitochondria, oxidative stress after massive oxygen radicals, the exhaustion of adenine nucleotide and mitochondrial membrane depolarization [19]. If the vicious cycle between ROS and mitochondria keeps going, cytochrome $\mathrm{C}$ will be released to activate the cascade of caspase-9, 8, 3 enzymes, which finally result in lymphocyte apoptosis. During apoptosis, ROS stimulates the opening up of MPTP and can also be produced as products during this stimulation. Hausenloy DJ,et al reported that MPTP may acts as a terminal effect factor regulating apoptosis, both as endogenous self activator and ROS initiation factors [20]. 
In this experiment, compared with the control group, lymphocytes with dropped mitochondrial membrane potential or abnormally opened MPTP from the SAP group got accelerated remarkably, which suggested that, during SAP, splenic lymphocytic mitochondrial membrane permeability enhanced and potentially decreasing, the mitochondrial apoptosis pathway played an important role in regulating apoptosis. UTI could effectively protect mitochondria through stabilizing mitochondrial membrane structure and enhancing the activity of mitochondrial $\mathrm{Na}^{+}-\mathrm{K}^{+}$-ATPase enzyme. Other studies found that UTI could lessen mitochondrial damages and inhibit apoptosis induced by mitochondrial pathway, through limiting the expressions of ischemia-reperfusion organic cytochrome $\mathrm{C}$ and AIF. During the experiment, it was found that ulinastatin could dramatically lower the ratio of lymphocytes with opened MPTP in SAP rats and the ratio with dropped MMP. It is finally demonstrated that UTI attenuates lymphocytes apoptosis and improves immunological function in SAP rats. It exerts the therapeutic effects through reducing ROS induced by SAP, blocking the vicious cycle between ROS and mitochondrial damage, thereby inhibiting the apoptosis induced by mitochondrial signaling pathways.

\section{CONFLICT OF INTEREST}

The authors have declared no conflict of interest.

\section{REFERENCES}

1. Martin MA, Saracibar E, Santamaria A, Arranz E, Garrote JA, Almaraz A, Del OM, Garcia-Pajares $F$ Fernandez-Orcajo $P$, Velicia $R$, Blanco-Quiros $A$, Caro-Paton A. Interleukin 18 (IL-18) and other immunological parameters as markers of severity in acute pancreatitis. Rev Esp Enferm Dig 2008; 100: 768-773.

2. Kylanpaa ML, Repo H, Puolakkainen PA. Inflammation and immunosuppression in severe acute pancreatitis. World J Gastroenterol 2010; 16: $2867-$ 2872.

3. Nathan C. Points of control in inflammation. Nature 2001; 420: 846-852.

4. Green DR, Kroemer G. The pathophysiology of mitochondrial cell death. Science 2004; 305: 626629.

5. Lin MT, Beal MF. Mitochondrial dysfunction and oxidative stress in neurodegenerative diseases. Nature 2006; 443: 787-795.

6. Kim SJ, Yoo KY, Jeong CW, Kim WM, Lee HK, Bae HB, Kwak SH, Li M, Lee J. Urinary trypsin inhibitors afford cardioprotective effects through activation of pi3k-akt and erk signal transduction and inhibition of p38 mapk and jnk. Cardiology 2009; 114: 264-270.

7. Yang $H$, Mao $Y, L u X$, Sang $X, D u S$, Zhao $H, X u Y, X u$ $H$, Yang Z, Chi T, Zhong S, Huang J. The effects of urinary trypsin inhibitor on liver function and inflammatory factors in patients undergoing hepatectomy: a prospective, randomized, controlled clinical study. Am J Surg 2011; 202: 151-157.

8. Uemura K, Murakami Y, Hayashidani $Y$, Sudo $T$, Hashimoto $Y$, Ohge $H$, Sueda $T$. Randomized clinical trial to assess the efficacy of ulinastatin for postoperative pancreatitis following pancreaticoduodenectomy. J Surg Oncol 2008; 98: 309-313.

9. Ma T, Kang C, Shao $H, Q i Q, H u W$. Protective effects of ulinastatin on proliferation and cytokine release of splenocytes from rats with severe acute pancreatitis. Eur Surg Res 2006; 38: 445-450.

10. Tanaka R, Fujita M, Tsuruta R, Fujimoto K, Aki HS, Kumagai K, Aoki T, Kobayashi A, Izumi T, Kasaoka $S$, Yuasa M, Maekawa T. Urinary trypsin inhibitor suppresses excessive generation of superoxide anion radical, systemic inflammation, oxidative stress, and endothelial injury in endotoxemic rats. Inflamm Res 2010; 59: 597-606.

11. Feng H, Guo L, Song Z, Gao H, Wang D, Fu W, Han J, Li Z, Huang B, Li XA. Caveolin-1 protects against sepsis by modulating inflammatory response, alleviating bacterial burden, and suppressing thymocyte apoptosis. J Biol Chem 2010; 285: 25154-25160.

12. Cicalese L, Sahai A, Sileri P, Rastellini C, Subbotin V, Ford $H$, Lee $K$. Acute pancreatitis and bacteria translocation. Dig Dis Sci 2001; 46: 1127-1132.

13. Watanabe $T$, Sato $Y$, Ichida $T$, Yamamoto $S$, Oya $H$, Nakatsuka $H$, Kobayashi $T$, Hatakeyama $K$. Comparison of urinary ulinastatin levels between donors and recipients immediately following adult living related donor liver transplantation. Transplant Proc 2003; 35: 76-77.

14. Huang SW, Chen J, Ouyang B, Yang $\mathrm{CH}$, Chen MY, Guan $X D$. Immunotherapy improves immune homeostasis and increases survival rate of septic patients. Chin J Traumatol 2009; 12: 344-349.

15. Wang YH, Feng ZJ, Hao X: Relationship between acute pancreatitis and oxidative stress. World Chin J Digestol 2007; 15: 1266-1272.

16. Zamzami $N$, Kroemer $G$. The mitochondrion in apoptosis: how pandora's box opens. Nat Rev Mol Cell Biol 2001; 2: 67-71.

17. Hiona $A$, Leeuwenburgh $C$. The role of mitochondrial dna mutations in aging and sarcopenia: implications for the mitochondrial vicious cycle theory of aging. Exp Gerontol 2008; 43: 24-33.

18. Callahan $L A$, Stofan DA, Szweda $L I$, Nethery $D E$, Supinski GS. Free radicals alter maximal diaphragmatic mitochondrial oxygen consumption in endotoxin-induced sepsis. Free radic Biol Med 2001; 30: 129-138.

19. Javadov S, Karmazyn M, Escobales N. Mitochondrial permeability transition pore opening as a promising therapeutic target in cardiac diseases. J Pharmacol Exp Ther 2009; 330: 670-678.

20. Hausenloy DJ, Yellon DM. Reperfusion injury salvage kinase signalling: taking a risk for cardioprotection. Heart Fail Rev 2007; 12: 217-234. 